\title{
Psychoanalysis using Software Simulation
}

\author{
Habib Shaikh \\ Department of \\ Information Technology \\ Vidyalankar Institute of \\ Technology \\ Mumbai, India
}

\author{
Rishabh Mehra \\ Department of \\ Information Technology \\ Vidyalankar Institute of \\ Technology \\ Mumbai, India
}

\author{
Sagar Mhatre \\ Department of \\ Information Technology \\ Vidyalankar Institute of \\ Technology \\ Mumbai, India
}

\author{
Deepali Vora \\ Department of \\ Information Technology \\ Vidyalankar Institute of \\ Technology \\ Mumbai, India
}

\begin{abstract}
Psychoanalysis is a concept related to the study of the unconscious mind, which is used by various companies during the process of hiring candidates.[1] The current system for recruitment procedure does not take into consideration all the aspects of an individual while taking an assessment test. According to researchers, it is seen that users tend to respond to interactive interfaces in an honest manner rather than faking it, which is the main disadvantage of the current system.[2] The proposed system's interactive interface is created by giving a pictorial representation of the situations. This helps us in forming a clear idea of the situation and eliminates the possibility of a wrong interpretation of the situations. The system generates two types of recommendations: one for user \& one for the HR person of the company. The system will recommend an appropriate job to the user based on demographic information, previous experience and the test given by the user. Based on test $\&$ user experience the human resource will be recommended to the Human resource (HR) person of the company.
\end{abstract}

\section{General Terms}

Psychometric test, candidate recommendation.

\section{Keywords}

Situational Judgment Test, Personality assessment, OCEAN personality model, Psychoanalysis.

\section{INTRODUCTION}

Personality assessment has always been an ideal tool for human civilization throughout history.[3] It has been creatively used in various ways - from job interviews to intelligent recommendation systems to self-reflection. In today's world, such tests are majorly used for assessing a candidate regarding their suitability for any given position in any project.[4]

Having a face-to-face interaction for the assessment of one's personality via a meeting with a psychologist is always a tedious and error-prone process. This issue is tackled by implementing online psychometric assessment tests that provide the candidate with a set of questions, with each question having a set of choices.[5]

The permutations and combinations of selection of these choices by the appearing candidate would determine their personality as each selected choice has one or more traits associated with it.

However, this developed solution is highly time-consuming \& can be manipulated easily according to natural human understanding of ideal responses to a given scenario.[6].

\section{LITERATURE SURVEYED}

The literature survey is research on publications concerning a subject.[7] Intense research has been conducted in order to get a gist of the current systems that are being used by industry. The proposed system uses inferences from the research and tries to overcome their limitations. A detailed table of research papers and the paper findings are provided in Table $\mathbf{1 .}$

Table 1: Summary of Literatures Reviewed

\begin{tabular}{|c|c|c|c|}
\hline Name of the paper & Year & Author & Inference \\
\hline $\begin{array}{l}\text { Psychometric Assessment and Its Impact } \\
\text { on Human Resource Practices.[8] }\end{array}$ & 2011 & Owen Fernandes & $\begin{array}{l}\text { Importance of Psychological tests in the } \\
\text { recruitment procedures. }\end{array}$ \\
\hline $\begin{array}{l}\text { Use of Psychometric tests in } \\
\text { recruitment.[9] }\end{array}$ & 2013 & Sayantany Paul & $\begin{array}{l}\text { How different Designations require different } \\
\text { skills to ponder up before evaluation. }\end{array}$ \\
\hline $\begin{array}{l}\text { A situational judgment test of professional } \\
\text { behavior: Development and validation.[10] }\end{array}$ & 2014 & Oliver Wilhelm & $\begin{array}{l}\text { An open question is the value of a written test to } \\
\text { predict job performance. } \\
\text { - In a paper and pencil test, student behavior } \\
\text { cannot be measured. } \\
\text { The "knows" and "knows how" level of } \\
\text { Miller' pyramid of clinical competence. }\end{array}$ \\
\hline Name of the paper & Year & Author & Inference \\
\hline $\begin{array}{l}\text { Optimizing the validity of situational } \\
\text { judgment tests: The importance of scoring } \\
\text { methods. [11] }\end{array}$ & 2018 & Filip Lievens & $\begin{array}{l}\text { - } \quad \begin{array}{l}\text { Take into consideration two types of scoring } \\
\text { procedures (mode and proportion consensus). }\end{array} \\
\text { - } \quad \text { Scoring alternatively and interactive scoring }\end{array}$ \\
\hline
\end{tabular}




\begin{tabular}{|c|c|c|c|}
\hline & & & approach. \\
\hline $\begin{array}{l}\text { Development of an Online Construct- } \\
\text { Informed Situational Judgment Test for } \\
\text { Screening Applicants for Initial Teacher } \\
\text { Education. [12] }\end{array}$ & 2018 & $\begin{array}{c}\text { Robert M. Klassen and } \\
\text { Lisa E. Kim }\end{array}$ & $\begin{array}{c}\text { • Teaching-focused SJT } \\
\text { Tool to assess certain aspects of candidates' } \\
\text { non-cognitive attributes, and especially situational } \\
\text { judgment, when they apply to ITE programs. }\end{array}$ \\
\hline $\begin{array}{l}\text { A 5-Minute Situational Judgment Test to } \\
\text { Assess Empathy in First-year Student } \\
\text { Pharmacists. [13] }\end{array}$ & 2018 & $\begin{array}{l}\text { Michael D. Wolcott, } \\
\text { Carly Lupton-Smith, } \\
\text { Wendy C. Cox, } \\
\text { Jacqueline E. } \\
\text { McLaughlin. }\end{array}$ & $\begin{array}{l}\text { - } \\
\text { SJT can be a feasible and efficient method to } \\
\text { assess students. } \\
\text { Evaluate design features } \\
\text { Pilot test items. } \\
\text { Develop a comprehensive plan for } \\
\text { implementation. }\end{array}$ \\
\hline $\begin{array}{l}\text { Optimizing the validity of situational } \\
\text { judgment tests: The importance of scoring } \\
\text { methods. [14] }\end{array}$ & 2018 & $\begin{array}{l}\text { Qingxiong WENG, } \\
\text { Hui YANG, Filip } \\
\text { LIEVENS, and } \\
\text { Michael A. } \\
\text { MCDANIEL }\end{array}$ & $\begin{array}{l}\text { Alternatives to the SJT scoring literature (i.e., } \\
\text { mode and proportion consensus) } \\
\text { One integrated scoring approach. } \\
\text { consensus scoring, versus Integrated scoring strategy. }\end{array}$ \\
\hline $\begin{array}{l}\text { Evaluating the Performance of Individuals } \\
\text { as Members of Small Groups. [15] }\end{array}$ & 1954 & $\begin{array}{l}\text { LAUNOR F. } \\
\text { CARTER }\end{array}$ & $\begin{array}{l}\text { - Individual prominence } \\
\text { - } \quad \text { Aiding attainment by the group } \\
\quad \text { Sociability }\end{array}$ \\
\hline $\begin{array}{l}\text { Situational Tests in Student Selection: An } \\
\text { Examination of Predictive } \\
\text { Validity, Adverse Impact, and Construct } \\
\text { Validity. [16] }\end{array}$ & 2002 & $\begin{array}{l}\text { Filip Lievens and Pol } \\
\text { Coetsier }\end{array}$ & $\begin{array}{l}\text { The use of situational tests in student selection } \\
\text { enables us to measure a broader range of skills and } \\
\text { abilities }\end{array}$ \\
\hline $\begin{array}{l}\text { Personnel Psychology: Studies of } \\
\text { Situational Tests. [17] }\end{array}$ & 1999 & $\begin{array}{l}\text { Jeff A. Weekley, } \\
\text { Casey Jones }\end{array}$ & $\begin{array}{l}\text { In the present paper, results are reported for two } \\
\text { different situational judgment tests (SJT) used in } \\
\text { validation studies with almost } 4,000 \text { employees in } 7 \\
\text { different organizations. Across the } 2 \text { studies, it was shown } \\
\text { that situational test scores were significantly related to } \\
\text { performance (weighted average } \mathrm{T}=0.19 \text { ), cognitive } \\
\text { ability (weighted average } \mathrm{T}=0.45 \text { ), and experience } \\
\text { (weighted average } \mathrm{r}=0.20 \text { ). }\end{array}$ \\
\hline
\end{tabular}

\section{PROPOSED SYSTEM}

In figure 1, the user registers and provides the website with details about his/her present educational details, their area of interest, certifications, etc. Once the registration process is done and the characteristics are stored the user is eligible to give the test.

The test provided to the user is generated by selecting several test scenes. The user answers this test by selecting the most viable option according to him/her out of the other four. Once the test is completed, the scores are evaluated by weight according to the requirements proposed by the Human Resource (HR) person of the company. The requirements proposed by the HR person decides the weight of each option.

The recommendation algorithm compares the HR person's requirements, the user's characteristics and his test score for the test generated. The outputs from this algorithm are candidate recommendations along with the user's test scores and their background which are presented to the HR person of the company.

Meanwhile, the user is provided with job recommendations that match his profile according to the test given. He may apply for the recommended jobs as well.

A detailed description of each of the components in the system diagram is as follows:

A. User

The user is the one who is interested in a company and is ready to go through the recommendation process provided by the proposed system. The user has to provide two basic inputs for the recommendation algorithm. One is to provide the details about themselves which are taken via the registration process conducted when the user initiates the system. Another input to the system is the score obtained by the user once the test is given.

B. Test Scenes and User's Score

The test scenes are nothing but a set of multiple-choice situation-based questions which have different weights assigned to each option depending on the type of situations and its ideal reaction. Scenes of each question are made using Adobe Photoshop which acts as a catalyst for the user performing the test to grasp details and relate to the situation 
easily. The options for the question are also made in Photoshop which is designed in such a way that it gives a smooth transition between the question and the options. The options are weighted based on the Big Five Personality traits also called as OCEAN (Openness, Conscientiousness,
Extraversion, Agreeableness, and Neuroticism) traits and type of job role the user is applying for. There is a total of 25 questions in the test which includes 2-4 options for each question and the questions are repeated too for checking fairness in the user's performance.

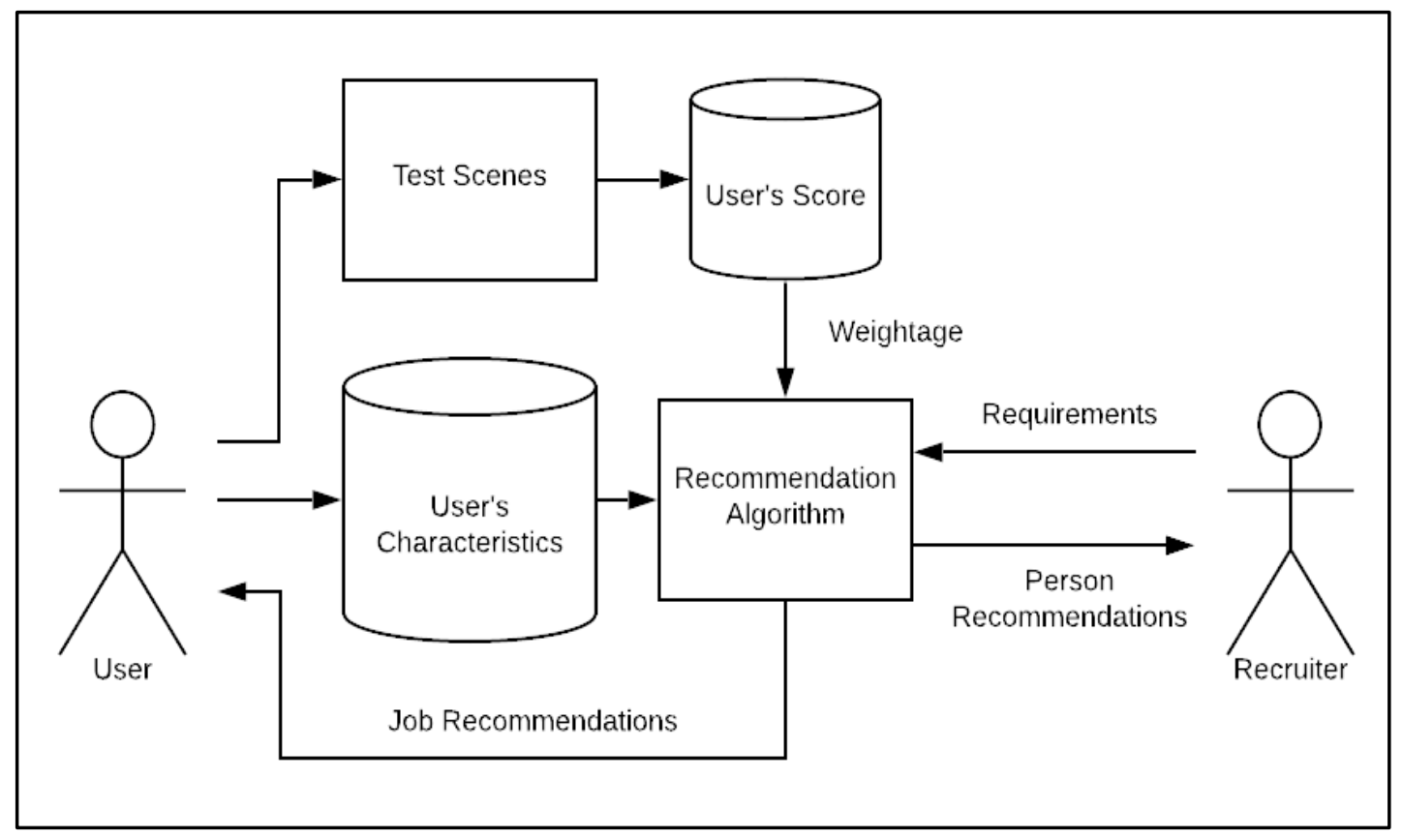

Figure 1: System Diagram

\section{User's Characteristics}

The user characteristics are one of the vital inputs provided by the user for the recommendation algorithm to work. User characteristics are taken with the help of a registration process which the user has to go through before being able to perform the test and use the system. The details taken include age, skills, highest qualification, etc. which are compared against the requirements given by various companies in order to generate a recommendation to the company as well as the user.

\section{Recommendation Algorithm}

The recommendation algorithm is the core component of the proposed system. It takes various parameters from the user's side as well as the recruiter's side and generates a recommendation to the user and recruiter. The inputs to the recommendation algorithm are weightage: generated based on the user's performance in the test, user characteristics: provided directly by the user, requirements: provided by the company recruiter.

\section{E. Recruiter}

HR is the one that is looking to hire candidates with the help of the proposed system. HR is responsible for providing the requirements to the system for which the system will generate recommendations.

\section{METHODOLOGY}

The methodology used to make the project is as follows:

\section{1) Data Gathering}

Various assessment tests were reviewed to get a clear idea of what type of questions needs to be covered, the time constraint and the scope of the project.

2) Creation of questions

To create the set of questions, multiple SJT's were taken and patterns of the questions used in those tests were found out.
The questions were selected in such a way that they were able to affect the major five traits that were taken into consideration.

3) Creation of cards

Each scene represents a single question, made in Photoshop having four choices.

4) Generation of data

The prototype was given to users for generating test data, the test takers were requested to provide their details such as qualification, age, the area of interest, etc.

5) Implementation of the algorithm on the data

To apply an algorithm, the data is visualized to have a clear representation of the dataset. The data points are plotted according to traits and overall score, then the personalized recommendation model on the same is applied.

6) Creating UI(User Interface)

The creation of UI included creating a website that will be used for taking the user details and making a web-based application for hosting the test. The UI is made using HTML(Hyper Text Markup Language), CSS(Cascading Style Sheets) and Photoshop.

7) Recommendation Generation

The recommendation is done by taking inputs from the employers about what type of candidates they are looking for, which was then given to the recommendation algorithm that recommended candidates from the data available by matching the attributes for the candidate and the requirements of the employer.

8) Report Generation

A report is generated at the end of the test and is provided to the candidate, it consists of the overall score of the candidate in each trait and the performance of the candidate in the process. A report of recommendation is also given to the 
employers so that they can get knowledge about the candidates that are being recommended.

9) Testing for improving accuracy

Finally, the complete project is tested by having candidates give the test and then verifying those results.

\section{CONCLUSION}

The proposed system serves as a viable recommendation system for the candidate selection process conducted by various companies. The HR person as well as the user gets practical recommendations which are provided by the proposed system, with the help of user's data and HR's requirements. The data taken at the user's end will result in building their profile. Data collected at the recruiter's end is used to evaluate the users registered to the system. The data will be fed to a recommendation algorithm that would generate appropriate reports \& recommendations for both the ends. This data that is fed to the algorithm consists of the user's characteristics, test scores, and the HR's requirements.

\section{REFERENCES}

[1] Wikipedia, "Psychoanalysis", January 2019, https://en.wikipedia.org/wiki/Psychoan analysis.

[2] Edward Helmes and Ronald R. Holden, January 1987, "Response styles and faking on Basic Personality Inventory", Journal of Consulting and Clinical Psychology.

[3] Wikipedia, January 2019, "Human factors and ergonomics", https://en.wikipedia.or g/wiki/Human_factors_and_ergonomics.

[4] SUSAN M. HEATHFIELD, " Cultural Fit Assessment When Interviewing Candidates", https://www.thebalancecareers.com/assess-cultural-fitwhen-interviewing-candidates-1918087, January 2019.

[5] REVELIAN, "The new generation of candidate assessment" https://www.revelian.com/employer/solution/gamebased-assessments/, December 2018

[6] Gill Plimmer, "How to cheat a psychometric test", https://www.ft.com/content/eeda84e4-b4f6-11e3-916600144feabdc0, February 2019.
[7] José Roberto Camacho, "What is a literature survey?", https://www.researchgate.net/post/What_is_a_literature_ survey, March 2019.

[8] Owen Fernandes, "Psychometric Assessment and Its Impact on Human Resource Practices", IEEE, 2011.

[9] Sayantany Paul, "Use of Psychometric test in recruitment", International Journal of Research in Management, 2013.

[10] Oliver Wilhelm, "A situational judgment test of professional behavior: Development and validation", IEEE, 2014

[11] Flip Lievens, "Optimizing the validity of situational tests: the importance of scoring methods", IEEE, 2018.

[12] Robert M. Klassen and Lisa E. Kim "Development of an Online Construct-Informed Situational Judgment Test for Screening Applicants for Initial Teacher Education", European Research Council, 2018.

[13] Michael D. Wolcott, Carly Lupton-Smith, Wendy C. Cox, Jacqueline E. McLaughlin. "A 5-Minute Situational Judgment Test to Assess Empathy in First-year Student Pharmacists", AJPE, 2018.

[14] Qingxiong WENG, Hui YANG, Filip LIEVENS and Michael A. MCDANIEL "Optimizing the validity of situational judgment tests: The importance of scoring methods" Journal of Vocational Behavior Volume 104, Pages 199-209, 2018.

[15] LAUNOR F. CARTER "Evaluating the Performance of Individuals as Members of Small Groups", Personnel Psychology, Volume 7, Issue 4, Pages 477-484, 1954.

[16] Filip Lievens and Pol Coetsier "Situational Tests in Student Selection: An Examination of Predictive Validity, Adverse Impact, and Construct Validity", International Journal of Selection and Assessment, Volume10, Issue4, Pages 245-257, 2002.

[17] Jeff A. Weekley, "Casey Jones Personnel Psychology: Studies of Situational Tests", Personnel Psychology, Volume 52, Issue 3, Pages 679-700, 1999. 